\title{
Production and characterization of nanocellular polyphenylsulfone foams
}

\author{
V. Bernardo*, J. Martín-de León, M.A. Rodríguez-Pérez \\ Cellular Materials Laboratory (CellMat), Condensed Matter Physics Department, University of Valladolid, Campus Miguel Delibes, Paseo de Belén no. 7, 47011 \\ Valladolid, Spain
}

\section{A R T I C L E I N F O}

\section{Article history:}

Received 12 January 2016

Received in revised form

19 April 2016

Accepted 1 May 2016

Available online 2 May 2016

Keywords:

Nanocellular foams

Nanocellular polymers

Nanoporous polymers

Polyphenylsulfone

Gas dissolution foaming

$\mathrm{CO}_{2}$ solubility

\begin{abstract}
A B S T R A C T
Nanocellular foams have been produced by means of a gas dissolution process using polyphenylsulfone (PPSU) as matrix polymer. Cell sizes in the range $20-30 \mathrm{~nm}$ and cell nucleation densities higher than $10^{15} \mathrm{~cm}^{-3}$ have been achieved for materials with relative densities in the range $0.65-0.75$. The influence of both saturation pressure and foaming temperature has been studied. On the one hand, it has been proved that there is a large influence of the amount of gas $\left(\mathrm{CO}_{2}\right)$ absorbed in the final cellular structure, in fact it has been found a critical $\mathrm{CO}_{2}$ uptake between $9 \%$ and $9.5 \%$ at which the cell sizes evolve from the micro to the nanoscale. On the other hand, it has been found that there is a wide range of foaming parameters (foaming time and foaming temperature) in which nanocellular foams can be produced.
\end{abstract}

(c) 2016 Elsevier B.V. All rights reserved.

\section{Introduction}

Nanocellular polymeric foams are a new generation of materials characterized by cell sizes in the nanometric range. These materials present unique properties due to the size of the cells and cell walls in the nanoscale $[1,2]$. Thus they have generated an important interest in the scientific community during the last few years.

Essentials topic in this area are to evaluate polymeric systems that could produce nanocellular foams using processing parameters easily available, and also to determine the processing window for these specific systems. For instance, it is well known than poly(methyl methacrylate) (PMMA) and copolymers based on PMMA can be used to produce nanocellular foams [2] using the socalled solid state foaming method [3]. Different foaming conditions can be used to obtain nanocells between 20 and $200 \mathrm{~nm}$ and relative densities around $0.4-0.5[4,5]$. For polycarbonate (PC) systems, Guo et al. [6] obtained cell sizes of the order of $20 \mathrm{~nm}$ and relative densities around 0.6 working with low saturation temperatures. Engineering polymers such as polysulfone (PSU) have been tested as well, producing nanocellular foams with cell sizes ranging $20-80 \mathrm{~nm}$ and relative densities of $0.6-0.8$ [7].

\footnotetext{
* Corresponding author.

E-mail addresses: vbernardo@fmc.uva.es (V. Bernardo), jmadeleon@fmc.uva.es (J. Martín-de León), marrod@fmc.uva.es (M.A. Rodríguez-Pérez).
}

In the line of these studies the present work is focused on studying the processing window to obtain nanocellular structures using a material that has not been previously used for this purpose. High-performance thermoplastic polyphenylsulfone (PPSU) has been used to produce materials with cells below $30 \mathrm{~nm}$. A previous work of Sun et al. [8] showed that PPSU can generate microcellular foams with cell sizes between 2 and $13 \mu \mathrm{m}$ and cell densities of $10^{10}-10^{11}$ nuclei $/ \mathrm{cm}^{3}$. Those foams were produced using the well know solid state foaming method at medium pressure ( $5 \mathrm{MPa}$ ). The high pressure system used in this work allows dissolving more gas in the polymeric matrix. Therefore more nucleation sites have been produced, reaching cell nucleation densities of the order of $10^{14}-10^{15}$ nuclei $/ \mathrm{cm}^{3}$. Moreover this paper shows the possibility of producing these structures in a wide range of saturation pressures, foaming temperatures and times.

\section{Experimental part}

\subsection{Materials}

Polyphenylsulfone 428310 (PPSU) was kindly supplied by Sigma-Aldrich Chemistry, S. L. in the form of pellets. The material used presents a density $(\rho)$ of $1290 \mathrm{~kg} / \mathrm{m}^{3}$ (measured at $25^{\circ} \mathrm{C}$ ) and a glass transition temperature $\left(\mathrm{T}_{\mathrm{g}}\right)$ of $220^{\circ} \mathrm{C}$ measured by DSC. 


\subsection{Samples production}

The material was processed into sheets $1.5 \mathrm{~mm}$ thick using a cold/hot plate press. The material was first molten at $320^{\circ} \mathrm{C}$ during $30 \mathrm{~min}$ in an air circulating furnace. Then, it was pressed under a constant pressure of $2.2 \mathrm{MPa}$ for $30 \mathrm{~min}$ at a temperature of $220^{\circ} \mathrm{C}$. Finally the sample was cooled under $2.2 \mathrm{MPa}$ of pressure. These sheets were cut into samples of $20 \times 20 \times 1.5 \mathrm{~mm}^{3}$ and used for the foaming experiments.

\subsection{Foaming tests}

Foaming experiments were performed in a high pressure vessel (model PARR 4681) provided by Parr Instrument Company. The pressure system comprises an accurate pressure pump controller (model SFT-10) provided by Supercritical Fluid Technologies Inc. With this pressure system a set of tests has been performed using a two-step foaming process. Samples were introduced in the pressure vessel under a certain pressure. After reaching a fully saturated sample the pressure was released and samples were removed from the pressure vessel and immersed in a thermal bath for foaming.

Saturation parameters have been chosen in order to obtain different amounts of $\mathrm{CO}_{2}$ uptake. Three saturation pressures have been selected: $6 \mathrm{MPa}, 15 \mathrm{MPa}$ and $30 \mathrm{MPa}$. Saturation temperature and saturation time were fixed at $25^{\circ} \mathrm{C}$ and $60 \mathrm{~h}$ for all the experiments. After saturation, the pressure was released at a high depressurization rate (100 MPa/s) by means of an electrovalve. The time between the release of pressure and foaming was $3 \mathrm{~min}$ and no foaming took place during this time. Finally, the samples were foamed in a thermal bath at different temperatures (from $150{ }^{\circ} \mathrm{C}$ to $220^{\circ} \mathrm{C}$ ) and times (from 1 to $5 \mathrm{~min}$ ).

\subsection{Characterization techniques}

Density of solid samples $\left(\rho_{\mathrm{s}}\right)$ was measured with a gas pycnometer (Mod. AccuPyc II 1340, Micromeritics), and density of foamed samples $\left(\rho_{\mathrm{f}}\right)$ was determined with the water-displacement method, based on Archimedes' principle, using the density determination kit for an AT261 Mettler-Toledo balance. Density of foamed samples was measured without removing the solid skin of the cellular materials. All the foamed samples presented a solid skin, characteristic of the foaming process used. The skin thickness was almost constant with for all the materials and always below $50 \mu \mathrm{m}$, so differences in density as a consequence of the solid skin are lower than a $4 \%$ in the range of densities measured (i. e. the different in density between samples with and without a solid skin was very small and for this reason all the data presented are for samples with skin). Relative density $\left(\rho_{\mathrm{r}}\right)$ has been calculated as $\rho_{\mathrm{f}} / \rho_{\mathrm{s}}$.

With the aim of maintaining the structure for the microscopic visualization, samples were cooled in liquid nitrogen, fractured and finally coated with gold using a sputter coater (model SCD 005, Balzers Union). The cellular structure of the samples was analyzed using an ESEM Scanning Electron Microscope (QUANTA $200 \mathrm{FEG})$. Cell nucleation density $\left(\mathrm{N}_{0}\right)$ has been determined with a software based on ImageJ/FIJI [9] based on the Kumar method [10]. Cell size $(\phi)$ has been calculated by averaging the cell size measured in a satisfactory number of cells (more than 50 cells).

The total amount of gas uptake was calculated as the percentage of weight increment of the sample due to the $\mathrm{CO}_{2}$ sorption. The final weight of the sample after the saturation process was evaluated from the desorption curve, which was registered with a Metler-Toledo balance, and extrapolating it to zero desorption time. Also this desorption curve has been used to calculate the desorption diffusivity using the slope method [11].

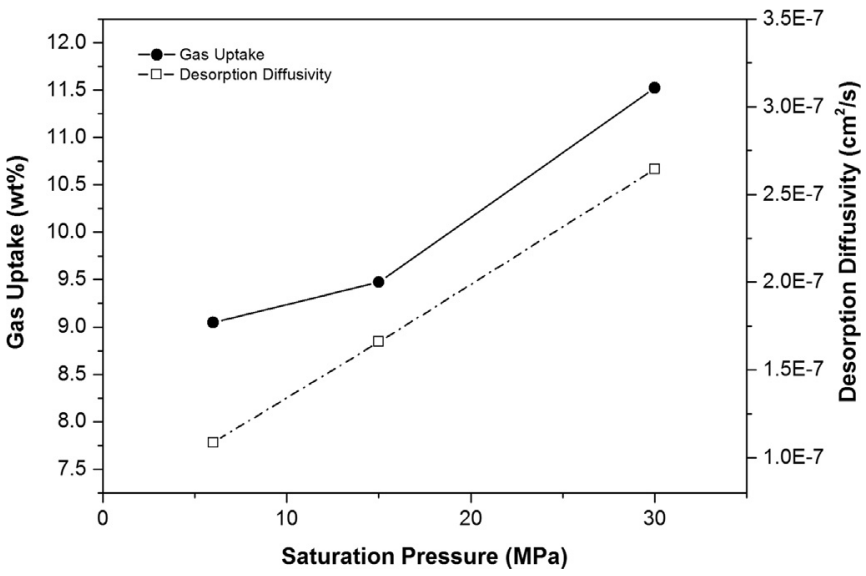

Fig. 1. Amount of gas uptake and desorption diffusivity as a function of the saturation pressure.

\section{Results}

\subsection{Gas uptake and diffusivity}

Three different saturation pressures $(6,15$ and $30 \mathrm{MPa})$ were used for this study. The amount of gas uptake at each pressure as well as the corresponding desorption diffusivities are shown in Fig. 1. As expected, these data clearly show that the amount of gas uptake decreases while decreasing the saturation pressure. However, and unlike other systems, the percentage of gas uptake does not decrease significantly even at $6 \mathrm{MPa}$. An $11.5 \%$ of $\mathrm{CO}_{2}$ is absorbed at $30 \mathrm{MPa}$, whereas at $6 \mathrm{MPa}$ this is still a very high value of around $9 \%$. In addition, desorption diffusivity values are in the same range of $10^{-7} \mathrm{~cm}^{2} / \mathrm{s}$ for the three analyzed pressures. Values are higher for the larger pressures, due to the higher plasticization effect of the $\mathrm{CO}_{2}$ when a higher amount of $\mathrm{CO}_{2}$ is dissolved.

\subsection{Influence of the foaming temperature and time}

The analysis of the influence of the foaming temperature was carried out using $30 \mathrm{MPa}$ as saturation pressure. Fig. 2 shows the evolution of the relative density as a function of the foaming time for different foaming temperatures. Density does not vary significantly with foaming time for any foaming temperature. Very high $\left(220^{\circ} \mathrm{C}\right)$ or very low $\left(150^{\circ} \mathrm{C}\right)$ temperatures provide the highest densities. The $\mathrm{T}_{\mathrm{g}}$ of the polymer is around $220^{\circ} \mathrm{C}$, which

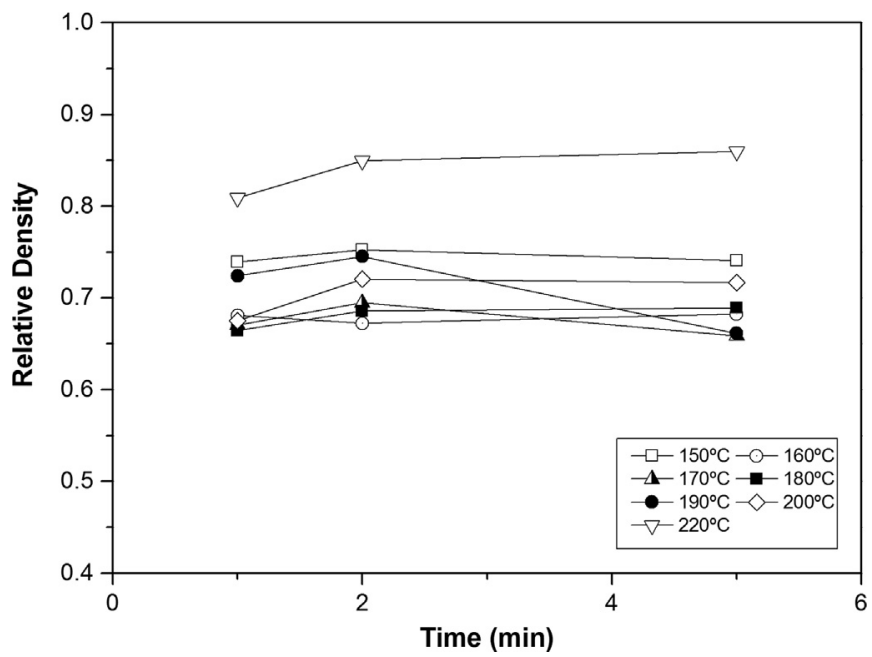

Fig. 2. Relative density as a function of the foaming time for the foaming temperatures under study. 
Table 1

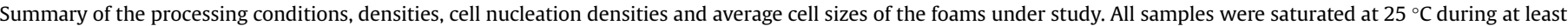
$60 \mathrm{~h}$ and foaming time was $1 \mathrm{~min}$.

\begin{tabular}{|c|c|c|c|c|c|c|c|}
\hline \# & $\begin{array}{l}\text { Saturation pressure } \\
\text { (MPa) }\end{array}$ & $\begin{array}{l}\text { Gas uptake } \\
\text { (wt\%) }\end{array}$ & $\begin{array}{l}\text { Foaming temperature } \\
\left({ }^{\circ} \mathrm{C}\right)\end{array}$ & $\begin{array}{l}\text { Relative } \\
\text { density }\end{array}$ & Cell nucleation density (nuclei $/ \mathrm{cm}^{3}$ ) & $\begin{array}{l}\text { Average cell size } \\
(\mathrm{nm})\end{array}$ & $\begin{array}{l}\text { Standard deviation } \\
(\mathbf{n m})\end{array}$ \\
\hline A1 & 30 & 11.5 & 150 & 0.739 & $2.96 \cdot 10^{15}$ & 21 & 9 \\
\hline A2 & 30 & 11.5 & 160 & 0.681 & $2.93 \cdot 10^{15}$ & 27 & 14 \\
\hline A3 & 30 & 11.5 & 170 & 0.670 & $3.02 \cdot 10^{15}$ & 25 & 12 \\
\hline A4 & 30 & 11.5 & 180 & 0.664 & $3.56 \cdot 10^{15}$ & 23 & 9 \\
\hline A5 & 30 & 11.5 & 190 & 0.724 & $1.95 \cdot 10^{15}$ & 21 & 15 \\
\hline A6 & 30 & 11.5 & 200 & 0.675 & $3.24 \cdot 10^{15}$ & 28 & 10 \\
\hline A7 & 30 & 11.5 & 220 & 0.809 & $1.07 \cdot 10^{15}$ & 27 & 11 \\
\hline B1 & 15 & 9.5 & 180 & 0.616 & $2.24 \cdot 10^{14}$ & 43 & 21 \\
\hline B2 & 15 & 9.5 & 200 & 0.601 & $8.47 \cdot 10^{14}$ & 56 & 26 \\
\hline B3 & 6 & 9.0 & 180 & 0.620 & $6.17 \cdot 10^{11}$ & 1050 & 950 \\
\hline B4 & 6 & 9.0 & 200 & 0.356 & $1.24 \cdot 10^{12}$ & 1220 & 820 \\
\hline
\end{tabular}
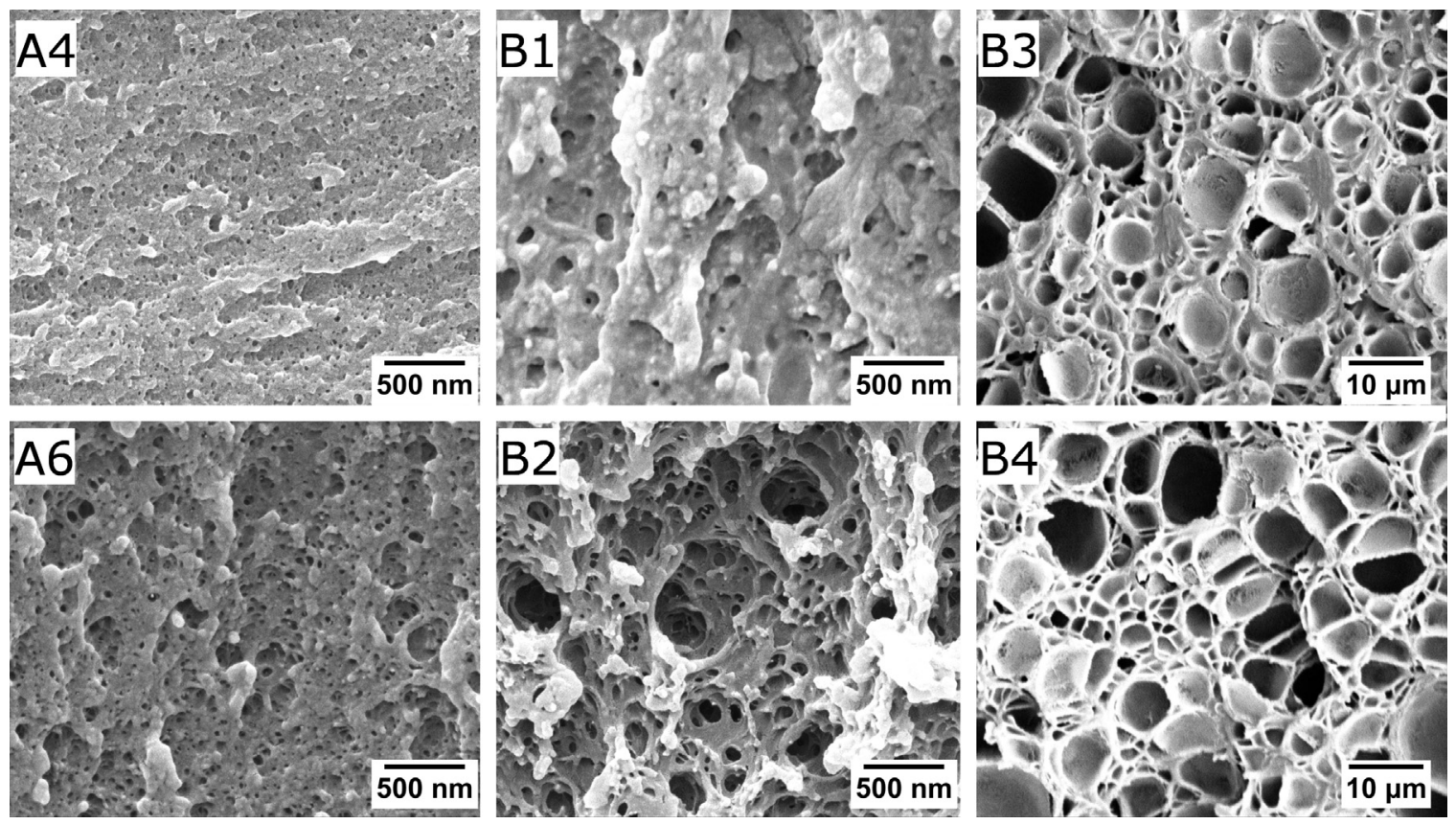

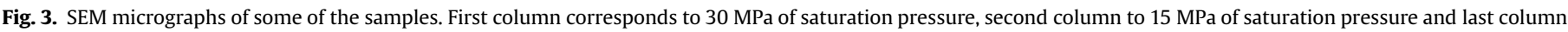
to $6 \mathrm{MPa}$ of saturation pressure. Samples of the first row were foamed at $180^{\circ} \mathrm{C}$ whereas those of the second row were foamed at $200{ }^{\circ} \mathrm{C}$.

explains the high density obtained by foaming at this temperature due to a possible collapse of the cellular structure.

As relative density is constant as a function of the foaming time, samples produced at 1 min were selected for the study of the cellular structure parameters. Processing conditions and cellular characteristics of these foams are summarized in Table 1 (samples from A1 to A7). Fig. 3 shows the cellular structure of some of the analyzed samples (samples A4 (foamed a $180^{\circ} \mathrm{C}$ ) and A6 (foamed at $200{ }^{\circ} \mathrm{C}$ )). All the foams produced at $30 \mathrm{MPa}$ show cell densities above $10^{15}$ nuclei $/ \mathrm{cm}^{3}$ and cell sizes in the range of $20-30 \mathrm{~nm}$. Therefore for this $\mathrm{CO}_{2}$ concentration, there is a wide window of foaming temperatures (between $150^{\circ} \mathrm{C}$ and $200{ }^{\circ} \mathrm{C}$ ) for the production of nanocellular foams with the aforementioned cell size and cellular densities.

\subsection{Influence of the saturation pressure}

In order to test how the cellular structure is affected by the amount of gas uptake, a set of foaming experiments were carried out using two different foaming temperatures, $180^{\circ} \mathrm{C}$ and $200{ }^{\circ} \mathrm{C}$, for the three pressures under study. Foaming time was fixed at $1 \mathrm{~min}$. Table 1 summarizes the cellular structure parameters of the foams produced at lower pressures (samples B1 to B4). Micrographs of the samples can be seen in Fig. 3. The lowest saturation pressure (6 MPa) provides microcellular foams with cell sizes larger than $1 \mu \mathrm{m}$. In this particular case the foam produced at $200{ }^{\circ} \mathrm{C}$ is the one with the lowest relative density (0.35).

The samples saturated at $15 \mathrm{MPa}$ present similar relative densities (around 0.6) for the two foaming temperatures and they also show very high cell densities (above $10^{14}$ ) and cell sizes in the nanoscale (around $50 \mathrm{~nm}$ ). This result proves that PPSU nanofoams can be produced not only at high pressures ( $30 \mathrm{MPa}$ ) but also at medium pressures (15 MPa). The amount of gas uptake is $11.5 \%$ and $9.5 \%$ respectively, and cell nucleation densities of the order of $10^{14}-10^{15}$ nuclei $/ \mathrm{cm}^{3}$ are obtained. However, decreasing the pressure to $6 \mathrm{MPa}$ reduces the amount of gas uptake by $0.5 \%$, and this is enough to reduce the cell nucleation density to around $10^{12}$ nuclei $/ \mathrm{cm}^{3}$ and increasing the cell size to the microscale. Therefore, we can conclude that there exists a critical gas concentration between $9 \%$ and $9.5 \%$ which allows creating a nanocellular structure. This critical $\mathrm{CO}_{2}$ mass uptake has been reported in different studies and for different systems. A similar result was observed for PSU by Guo et al. [7] they found a critical gas uptake between $10 \%$ and $12 \%$. For materials like PEI, the critical 
concentration is similar to the PPSU one, between $9.4 \%$ and $11 \%$ [12] while there are polymers that need higher gas concentrations in order to lead nanocells. For instance, for PMMA the critical concentration is between $30.1 \%$ and $32.6 \%$ [4], and for PC this value is between $15.9 \%$ and $18.9 \%$ of gas uptake [6].

\section{Conclusions}

Nanocellular foams based in polyphenylsulfone (PPSU) have been produced using a gas dissolution foaming technique. Materials with average cell sizes in the range between 21 and $56 \mathrm{~nm}$ range and cell nucleation densities of $10^{14}-10^{15}$ nuclei/ $/ \mathrm{cm}^{3}$ have been produced. Relative densities between 0.65 and 0.75 have been obtained. A wide range of saturation pressures (between 15 and $30 \mathrm{MPa}$ ) and foaming temperatures (from $160{ }^{\circ} \mathrm{C}$ to $200{ }^{\circ} \mathrm{C}$ ) allow producing these materials. In addition, it has been proved that it is necessary to reach a critical concentration of gas uptake, between $9 \%$ and $9.5 \%$, to generate the nanocellular structure.

\section{Acknowledgements}

Financial support from FPU grant FPU14/02050 (V. Bernardo) from the Spanish Ministry of Education and Junta of Castile and Leon grant Q4718001C (J. Martín-de León) is gratefully acknowledged. Financial assistance from MINECO (MAT 2012-34901 and MAT2015-69234-R) and the Junta of Castile and Leon (VA035U13) is gratefully acknowledged.

\section{References}

[1] S. Costeux, $\mathrm{CO}_{2}$-blown nanocellular foams, J. Appl. Polym. Sci. 131 (2014) 41293.

[2] B. Notario, J. Pinto, M.A. Rodriguez-Perez, Towards a new generation of polymeric foams: PMMA nanocellular foams with enhanced physical properties, Polymer 63 (2015) 116-126.

[3] J.E. Martini-Vvedensky, N.P. Suh, F.A. Waldman, Microcellular Closed Cell Foams and their Method of Manufacture, US Patent 4,473,665.

[4] H. Guo, A. Nicolae, V. Kumar, Solid-state poly(methyl methacrylate) (PMMA) nanofoams. Part II: low-temperature solid-state process space using $\mathrm{CO}_{2}$ and the resulting morphologies, Polymer 70 (2015) 231-241.

[5] J. Pinto, M. Dumon, M. Pedros, J. Reglero, M.A. Rodriguez-Perez, Nanocellular CO2 foaming of PMMA assisted by block copolymer nanostructuration, Chem. Eng. J. 243 (2014) 428-435.

[6] H. Guo, V. Kumar, Some thermodynamic and kinetic low-temperature properties of the $\mathrm{PC}-\mathrm{CO}_{2}$ system and morphological characteristics of solid-state PC nanofoams produced with liquid $\mathrm{CO}_{2}$, Polymer 56 (2015) 46-56.

[7] H. Guo, A. Nicolae, V. Kumar, Solid-state microcellular and nanocellular polysulfone foams, J. Polym. Sci. Part B: Polym. Phys. 53 (2015) 975-985.

[8] H. Sun, G.S. Sur, J.E. Mark, Microcellular foams from polyethersulfone and polyphenilsulfone. Preparation and mechanical properties, Eur. Polym. J. 38 (2002) 2373-2381.

[9] J. Pinto, E. Solórzano, M.A. Rodríguez-Pérez, J.A. de Saja, Characterization of the cellular structure based on user-interactive image analysis procedures, J. Cell. Plast. 49 (6) (2013) 555-575.

[10] V. Kumar, Process Synthesis for Manufacturing Microcellular Thermoplastic Parts (Ph.D. thesis), Massachusetts Institute Of Technology, Cambridge, MA, 1988.

[11] J. Crank, The Mathematics of Diffusion, 2nd ed., Brunel University Uxbridge: Claredon Press, Oxford, 1975.

[12] C. Zhou, N. Vaccaro, S.S. Sundarram, W. Li, Fabrication and characterization of polyetherimide nanofoams using supercritial $\mathrm{CO}_{2}$, J. Cell. Plast. 48 (3) (2012) 239-255. 